\title{
Modelling addition and replacement mechanisms of plasmid-based beta- lactam resistant E. coli infections
}

\author{
Noortje G. Godijk ${ }^{{ }_{1}}$, Martin C.J. Bootsma ${ }^{1,2}$, Henri C. van Werkhoven ${ }^{1}$, Valentijn A. Schweitzer ${ }^{1}$, \\ Sabine C. de Greeff ${ }^{3}$, Annelot F. Schoffelen ${ }^{3}$, Marc J.M. Bonten ${ }^{1}$ \\ 1 Julius Center for Health Sciences and Primary Care, University Medical Center Utrecht, Utrecht \\ University, Utrecht, 3584 CX Utrecht, the Netherlands. \\ ${ }^{2}$ Department of Mathematics, Faculty of Sciences, Utrecht University, Utrecht, Utrecht 3508 TA, the \\ Netherlands \\ ${ }^{3}$ Centre for Infectious Disease Control, National Institute for Public Health and the Environment (RIVM), \\ Bilthoven, Utrecht $3721 \mathrm{MA}$, the Netherlands \\ "Corresponding author: Noortje G. Godijk, $+31(0) 887568147$, University Medical Center Utrecht, Postbox \\ 85500, 3508 GA Utrecht, n.g.godijk-2@umcutrecht.nl
}

Author Contributions: N.G.G., M.C.J.B. and M.J.M.B. designed the research; H.C.W., V.A.S., S.C.G., and A.F.S. reviewed the design; N.G.G. implemented the model, performed the research and analyzed the data; S.C.G. and A.F.S. contributed the results on BSI in the Netherlands; N.G.G. drafted the manuscript; M.C.J.B., H.C.W., V.A.S., S.C.G., A.F.S and M.J.M.B reviewed the manuscript.

Competing Interest Statement: The authors declare no competing interest.

Keywords: Antibiotic resistant bacteria, resistance, addition, replacement. ESBL E. coli 
medRxiv preprint doi: https://doi.org/10.1101/2021.03.17.21253797; this version posted March 20, 2021. The copyright holder for this preprint (which was not certified by peer review) is the author/funder, who has granted medRxiv a license to display the preprint in perpetuity.

It is made available under a CC-BY-NC-ND 4.0 International license .

\begin{abstract}
It is unknown whether antibiotic-resistant bacterial infections occur in addition to antibiotic-susceptible bacterial infections, thereby increasing the infection incidence, or whether they replace such infections, leaving total incidence unaffected. Observational longitudinal studies cannot separate both mechanisms. Using plasmid-based beta-lactam resistant E. coli as example, we applied a mathematical neutral null model to investigate whether biological mechanisms implying either a fitness cost or a benefit due to resistance lead to replacement or addition. Fitness costs cause resistant strains to die out if other strain characteristics are maintained equal. Under the assumptions tested, only increased virulence increases the total number of infections, while other of resistance lead to replacement without changing the total number of infections. As there is no biological evidence that plasmid-based beta-lactam resistance increases virulence, these findings suggest that the burden of disease is determined by attributable effects of resistance rather than by an increase in infections.
\end{abstract}


medRxiv preprint doi: https://doi.org/10.1101/2021.03.17.21253797; this version posted March 20, 2021. The copyright holder for this preprint (which was not certified by peer review) is the author/funder, who has granted medRxiv a license to display the preprint in perpetuity. It is made available under a CC-BY-NC-ND 4.0 International license .

\section{Introduction}

It is unknown to what extent the global increase in infections caused by antibiotic-resistant bacteria (ARB) during the last decades has changed the burden of disease. ARB infections may occur on top of infections caused by non-ARB, a scenario labelled as addition (1), but they may also replace non-ARB infections. Infections caused by ARB are more difficult to treat, resulting in more adverse health outcomes (2), which increases the healthcare burden.

In the addition scenario, there is an increase in the total number of infections together with attributable harm created by those infection caused by ARB. In the replacement scenario, the increased burden of disease due to resistance results solely from the attributable harm created by resistant compared to susceptible infections, as the total number of infections remains stable. Quantifying the relative contribution of both scenarios is of critical importance for quantifying the burden of disease created by ARB. Longitudinal observational data have been used to estimate the relative importance of addition and replacement $(1,3)$, but the validity of these approaches suffered - inevitably - from other time-dependent changes and between study-groups differences that may influence overall incidence of infections, e.g., changes in medical procedures, population age, antimicrobial stewardship, and infection prevention measures.

As shown in Figure 1 occurrence of addition or replacement of infections caused by ARB cannot be deduced from observed time trends. Figure 1a depicts a scenario with an unobserved history and observed time trends of infections. Figures $1 \mathrm{~b}$ - $\mathrm{d}$ depict three different scenarios that can explain the same observed time trend namely, addition, replacement or a combination of the two. The scenarios depicted in Figure $1 \mathrm{~b}-\mathrm{d}$ have an equal number of resistant and susceptible infections and are compatible with the observed data. Changing the unobserved prevalence suggests a different interpretation on whether addition or replacement occurs. However, as the history is unobserved it cannot be decided based on time trend data whether addition or replacement has occurred. To illustrate this with real observational data, we determined the ESBL E. coli bacteraemia prevalence in the Netherlands between 2014 and 2019.

We, therefore, developed a mathematical model, comprising three populations, hospitalized patients, recently hospitalized patients and the general population to determine effects of various explicitly stated biological mechanisms that may change ARB carriage and subsequent infection, and thereby estimate whether these mechanisms cause replacement of or addition to susceptible infections. We start with a neutral mathematical model and in the base-case scenario we assume that susceptible and resistant strains co-exist at any ratio if the two strains behave identical in all aspects (4). Next we modify the characteristics of the ARB strain to create benefits or costs of resistance. A fitness advantage for ARB will ultimately lead to dominance of ARB variants over non-ARB strains (5). Multiple mechanisms can create a dynamical advantage of resistant above susceptible strains $(6,7)$. Similarly, resistance can be associated with a fitness cost, which fuelled the hope that natural selection would - in the absence of beneficial selective pressure - eventually lead to a reduction in ARB (8). Obviously, ARB (dis)advantages change in the context of antibiotic exposure. We focus on mechanisms that influence the prevalence of colonisation with ARB and non-ARB and keep host mechanisms affecting individuals' risks of acquisition of carriage or infection stable.

First, we study two mechanisms with a cost of resistance (i.e., increased clearance and decreased growing rates of ARB), and subsequently five mechanisms that benefit ARB. The first is increased virulence, defined as an increased probability to develop infection once colonisation has been established. This increased risk of infection may result from three separate mechanisms that have the same dynamical effects in our model, such as an increased bacterial load, higher intrinsic virulence of a bacterium, and failure of antibiotic prophylaxis $(6,9,10)$. The second is increased transmission, which leads to more ARB acquisitions and, thereby, to more subsequent infections, despite a stable infection rate (11). The third is lower clearance, which makes ARB carriage more persistent, prolonging the risk period for infection, despite a stable infection rate (12). The fourth is within-host plasmid transfer of resistance to susceptible strains, which increases the number of ARB strains and subsequently ARB infections. The fifth is selective antibiotic pressure, which increases probabilities of ARB acquisitions 
medRxiv preprint doi: https://doi.org/10.1101/2021.03.17.21253797; this version posted March 20, 2021. The copyright holder for this preprint (which was not certified by peer review) is the author/funder, who has granted medRxiv a license to display the preprint in perpetuity. It is made available under a CC-BY-NC-ND 4.0 International license .

through cross-transmission due to lower density of susceptible bacteria in subjects receiving antibiotics, increasing susceptibility to acquisition with resistant bacteria.

Moreover, we model two scenarios of combined mechanisms. The "mixed scenario" combines increased ARB hospital transmission and increased ARB clearance in the open population, thereby maximizing ARB benefits among hospitalized patients, e.g., due to high selective antibiotic pressure, and maximizing fitness costs of ARB in the absence of selective antibiotic pressure. The "double benefit scenario" combines increased ARB virulence and increased hospital transmission of ARB (through increased selective antibiotic pressure and higher contact rate by hospital staff acting as potential vectors), thereby maximizing ABR benefits in hospitalized patients.

We focus on $E$. coli with plasmid-based beta-lactam resistance, since these are widely prevalent in the population and an important cause of both community-acquired and hospital-acquired infections (13). Moreover, ESBL and carbapenem resistant $E$. coli have been set as a critical priority for research and development by the WHO on the global list of ARB (14).

\section{Results}

From 2014 till 2019 the ESBL E. coli bacteraemia prevalence in the Netherlands remained stable at around $5.4 \%$, but the total number of $E$. coli bacteraemia increased annually with $3.4 \%$ (Table S1 and Figure 2). Using the scenarios depicted in Figure 1, the observed time trend could reflect both addition to and replacement of susceptible E. coli bacteraemia (Figure 2).

In the neutral model, of 100,000 subjects, 177 were hospitalised, 694 were former patients and 99,129 were in the open population. Numbers of plasmid-based beta-lactam resistant and susceptible $E$. coli infections were 122 and 2,320 per 100,000 subjects annually. Infections caused by ARB occurred predominantly in former $(n=67)$ and hospitalised patients $(n=34)$, and 21 occurred in the open population. Infections by non-ARB also occurred predominantly in former $(n=1,275)$ and hospitalised patients $(n=651)$, and less frequently in the open population $(n=395)$. The infection incidence caused by ARB and non-ARB together is $8 \%$ per year in the hospital, $16 \%$ in former patients and $0.5 \%$ in the open population, yielding an infection incidence in the population (former patients and open population) of $2 \%$ per year.

The effects of changing rates related to costs and benefits of ARB in 10 years are depicted in Figure 3. Naturally, introducing costs of resistance without benefits of resistance reduces the incidence of infections caused by ARB and eventually leads to extinction (Figure S4 and Table S7). Whereas introducing a benefit without costs of resistance leads to replacement or addition.

Increased ARB virulence is associated with a linear increase in the incidence of infections caused by ARB: a $10 \%$ increased virulence leads to a $10 \%$ increase of infections caused by ARB with an unchanged incidence of infections caused by non-ARB. Thus, increased virulence leads to an equivalent addition to the total number of infections. The transmission rates, e.g. from $S$ to $R$ or $R$ to $R R$, are not affected by increased virulence and the subsequent increase in the incidence of ARB infections. Because the transmission dynamics are not altered by increased virulence, resistant and susceptible strains coexist in our model, which precludes eradication of susceptible strains.

The other four mechanisms associated with a dynamical benefit of $A R B$, all do lead to more infections caused by ARB, but only through replacing infections caused by non-ARB. In fifty years, a $10 \%$ increase in ARB transmission rates leads to a $13 \%$ increase in infections caused by ARB and a $50 \%$ decreased clearance of ARB leads to a $72 \%$ increase in infections caused by ARB which increases the prevalence of carriage with ARB from $5 \%$ to $8.6 \%$. The total number of infections remains stable. Introduction of plasmid acquisition also causes a linear replacement of infections caused by non-ARB. In 10 years, the number of infections caused by ARB increases with $67 \%$.

Administering a new course of antibiotics that clears 50\% of non-ARB E. coli results in replacement of non-ARB. Restricting the use of a course of antibiotics in hospitalized patients only, reduces replacement of infections caused by non-ARB (Figure 3). 
medRxiv preprint doi: https://doi.org/10.1101/2021.03.17.21253797; this version posted March 20, 2021. The copyright holder for this preprint (which was not certified by peer review) is the author/funder, who has granted medRxiv a license to display the preprint in perpetuity. It is made available under a CC-BY-NC-ND 4.0 International license .

Contrary to all other mechanisms, effects of increased virulence are not time dependent, as shown in the equal trends in Figure S2 and S3. This implies that an increase in virulence leads immediately to additional infections and this increase then remains stable. Other mechanisms benefitting ARB will lead to complete replacement of non-ARB, whereas increased virulence will lead to more infections without extinction of infections caused by non-ARB (Figure S3 and Table S6). Costs of resistance will lead to replacement of $A R B$.

Finally, we investigated two scenarios with combined mechanisms. The mixed scenario provides maximum benefits for ARB among hospitalized patients, but also maximum fitness costs of resistance in the absence of selective antibiotic pressure. In this scenario the incidence of infections caused by ARB declines with $18 \%$ (after 50 years), whereas the incidence of infections caused by non-ARB increases (with 1\%), leaving the total number of infections unaffected. In the double benefit scenario (with double benefits for ARB due to increased virulence and more transmission in hospitals) the incidence of infections caused by ARB would increase with a factor 5.75 (after 50 years), at the cost of infections caused by non-ARB (-25\%), and with a $5 \%$ increase in the total number of infections (Table S3).

\section{Discussion}

The modelling of different biological mechanisms affecting E. coli with and without plasmid-based betalactam resistance revealed that increased virulence is the only mechanism that would lead to a higher burden of infections due to emerging antibiotic resistance. Such an increase in the incidence of infections would occur instantaneously and linearly, without affecting the number of infections caused by non-ARB. All other biological mechanisms investigated, such as increased transmission, decreased clearance, plasmid transfer, and selection through antibiotic use resulted in scenarios in which infections caused by ARB would increase at the cost of infections caused by non-ARB, with a stable overall incidence of infections. Moreover, if resistance has both costs and benefits, emergence may lead to a stable coexistence of susceptible and resistant strains, for instance if resistance is beneficial in one niche, e.g., the hospital, but disadvantageous in the community, as reflected in the mixed scenario.

The starting point of this work was the recognition of difficulties in interpreting observational longitudinal data on antibiotic resistance prevalence. In the Netherlands the incidence of $E$. coli bacteraemia increased over time towards a stable prevalence of ESBL-producing E. coli bacteraemia (Figure 2). Yet, where the prevalence of ESBL-producing strains among $173 \mathrm{E}$. coli bacteraemia isolates was zero around 2000 in the Netherlands (15), it was around 5\% in 2014. With a stable population size and unchanged hospital policies related to infection diagnosis the $5 \%$ increase in resistance in-between both time points could have resulted from both addition and replacement mechanisms.

The biological plausibility of some of the biological mechanisms that we studied is not obvious. For instance, there is no biological prove that resistance in itself increases virulence (8). If ARB would not have increase virulence, the possibility of the addition scenario would be excluded as we found that only increased virulence results in additional infections. Furthermore, the dogma that antibiotic resistance, such as ESBL-production in E. coli, is associated with fitness costs has been questioned $(6,8,16)$. Indeed, if resistance comes without fitness costs through, for instance, increased clearance or decreased growth, ESBL-producing $E$. coli will not to be completely replaced by susceptible $E$. coli and will persist, even in the absence of antibiotic selective pressure.

Two previous studies attempted to disentangle whether a longitudinal increase in the incidence density of infections caused by ARB resulted from replacement or addition. Firstly, de Kraker et al. (17) investigated bacteraemia trends of five pathogens; Staphylococcus aureus, E. coli, Streptococcus pneumoniae, Enterococcus faecalis and Enterococcus faecium, using the European Antimicrobial Resistance Surveillance System (EARSS) database from 2002 to 2008. They report an increasing incidence in bacteraemia and suggested that this was mainly driven by resistant strains, implying that resistant clones add to rather than replace infections caused by susceptible bacteria. Secondly, Ammerlaan et al. (1) investigated temporal trends in annual incidence densities (events per 100,000 patient-days) of nosocomial bloodstream infections caused by methicillin-resistant Staphylococcus aureus (MRSA), ARB other than MRSA and non-ARB in 14 hospitals between 1998 and 2007. Seven hospitals had high incidence of MRSA infection in 1998 and no specific program to control the spread of MRSA. The other seven hospitals had low incidence of nosocomial infections with MRSA and infection control programs to 
medRxiv preprint doi: https://doi.org/10.1101/2021.03.17.21253797; this version posted March 20, 2021. The copyright holder for this preprint (which was not certified by peer review) is the author/funder, who has granted medRxiv a license to display the preprint in perpetuity. It is made available under a CC-BY-NC-ND 4.0 International license .

maintain low incidence levels of MRSA over this period. During the 10-year period the increase in the incidence density of non-ARB infections was similar in both hospital groups. Yet, the incidence of infections caused by ARB increased from 3.0 to 4.7 per 100,000 patient-days between 1998 and 2007 in hospitals that effectively controlled ARB infections, and from 4.6 to 29.1 per 100,000 patient-days between 1998 and 2007 in hospitals with pre-existing higher MRSA and ARB infection rates. From this the authors concluded that ARB infections were additive to non-ARB infections. The observed increase in incidence density of ARB was 10-fold higher than in non-ARB. Based on the findings in the current study, for such an increase to be fully explained by addition would require a similar (i.e., linear) increase in bacterial virulence (Supplementary text 5 and Table S8). It, therefore, seems more plausible that also in these hospitals replacement had occurred rather than addition.

A limitation of our study is that colonisation density is not modelled quantitatively, precluding modelling of within-host competition between strains. Yet, dynamics of within-host competition have not been accurately determined and it is, therefore, unknown, whether addition of this component improves modelling of the population level colonisation prevalence and infection incidence. Further, we limit acquisition routes of plasmid-based beta-lactam resistant $E$. coli and $E$. coli to humans, neglecting other reservoirs, such as livestock. Recent findings reported by Mughini-Gras et al. (18) imply that - at least in the Netherlands - the human reservoir is largely responsible for transmission among humans, with relatively little contribution of the animal reservoir.

In our study we explicitly investigate the effects of multiple mechanisms on the incidence of infections caused by ARB using a single model, which can also be used for other pathogens and in which other mechanisms can be included. In the current analyses the assumption that all individuals carry $E$. coli is vital. Investigating dynamics of pathogens for which this assumption does not hold, such as Staphylococcus aureus, would require an additional compartment for uncolonised subjects.

Increased virulence of $A R B$, compared to non-ARB, is the only mechanism studied that would increase the total number of infections due to emergence of ARB. Other mechanisms, such as increased transmission, decreased clearance, plasmid transfer, and antibiotic use result in replacement of non-ARB infections by ARB infections, with a stable incidence of the total number of infections.

\section{Methods \\ Time trend data}

As an illustration of the use of time trend data to estimate addition and replacement, we estimated changes in the prevalence of ESBL in community-acquired $E$. coli bacteraemia in the Netherlands from 2014 to 2018. We used data from the national surveillance system of antimicrobial resistance (ISIS-AR) based on routinely collected data from medical microbiological laboratories (19). We selected bloodisolates containing $E$. coli (one isolate per patient per year) with a sample moment maximum two days after hospital admission, or sampled at the emergency department or outpatient clinic, to define community-acquired bacteraemia. ESBL E. coli were determined based on ESBL-confirmatory tests or resistance to cefotaxime/ceftriaxone and/or ceftazidime, according to local practice. For the analysis, 24 hospitals with complete data available for the total study period were used.

\section{Theoretical framework}

To study the effects of seven mechanisms on the number of $E$. coli and plasmid-based beta-lactam resistant E.coli, we use a continuous time deterministic model, similar to Cooper et al. (20), consisting of a hospital population, a population of recently discharged patients, and an "open" population (Figure 4a). The total population size is constant and we ignore death and birth rates as these are substantially smaller than transmission and decolonisation rates in most parts of the population. Hospitalized patients are discharged to the former patient population at a constant rate. Subjects are hospitalized at constant rates, with a higher rate in the former patient population. Former patients transit to the open population at constant rates, after which their hospital admission rate becomes lower.

We assume homogeneous mixing in the hospital, allowing transmission between hospitalized patients at a rate four times higher than in the open population due to frequent contacts with healthcare workers and medical devices that may act as vectors for transmission. Among former patients the transmission rate is assumed to be higher compared to the open population, also because of interactions with healthcare 
medRxiv preprint doi: https://doi.org/10.1101/2021.03.17.21253797; this version posted March 20, 2021. The copyright holder for this preprint (which was not certified by peer review) is the author/funder, who has granted medRxiv a license to display the preprint in perpetuity. It is made available under a CC-BY-NC-ND 4.0 International license .

workers (21). Further, transmission occurs between and within the former patient and open population, which is one homogeneously mixed community, but we assume no transmission between the community and the hospital. We use frequency-dependent transmission based on the total fraction of colonised individuals. Mathematically, it means that the rate at which an individual acquires an $E$. coli strain is proportional to the fraction of individuals colonised with that strain. Moreover, the three populations have equal ARB decolonisation rates and transition rates between populations are independent of colonisation status. Table S4 presents the model parameters.

\section{Base-case scenario}

We developed a neutral null base-case model for resistant and susceptible bacteria which are indistinguishable except for their antibiotic susceptibility. In a neutral null model neither strain can have a selective advantage and the prevalence ratio of the two strains should remain constant over time (4). In our base-case, we assume no antibiotic use and, therefore, the base-case model lacks an intrinsic mechanism to promote stable coexistence between strains. When we consider other scenarios, we explicitly state the selective (dis)advantages of a strain (4). We choose a starting ARB colonisation prevalence of $5 \%$ in all populations (22).

In our model, individuals can be colonized with resistant strains (R-compartment), susceptible strains (Scompartment) or both (SR-compartment). As we assume that subjects are always colonized with the bacterium, there is no compartment of uncolonized subjects. Individuals in the S-compartment may acquire ARB and then move to the SR-compartment. Similarly, individuals in the R-compartment move to the SR-compartment after acquisition of susceptible strains. To maintain neutrality in absence of selective advantages, we added SS and RR compartments(4), even though they have no obvious biological meaning. Without these compartments, introduction of ARB into a population in which everyone could acquire ARB would lead to an equilibrium prevalence of $50 \%$, even in absence of selective advantages. Therefore, subjects colonised with susceptible (S) or resistant strains (R) remain susceptible to other strains as long as they are "low density colonised". Once progressed to "high density colonised" (labelled SS, RR or SR) they are non-susceptible to acquisition. We interpret RR, SR and SS-compartments as stable intestinal flora, preventing colonisation with other bacteria.

Infection rates are equal in high- and low-density compartments and proportional to the number of subjects colonised with resistant and susceptible strains. In the SR-compartment, the infection rate is the average of the S- and R-compartment, with infections with resistant or susceptible strains being proportional to the two infection rates. Differential equations specifying these models are given in Supplementary text 1. E. coli colonisation states are depicted in Figure 4b.

\section{ARB benefits and costs}

To investigate the dynamical effects of benefits and costs of resistance, we distinguish seven mechanisms, and determine the effects by gradually increasing or decreasing the applicable rates with $10 \%$ to $100 \%$, compared to the rate in the neutral model. Mechanisms benefitting resistant strains and increasing ARB colonisation prevalence render less people susceptible for acquiring new colonisation with susceptible strains, since we assume a maximum colonisation capacity (RR, SR or SS). Details of these biological mechanisms are described in Table S2.

The mechanism of plasmid transfer was restricted to within-host and within-species transfer, thereby increasing the transition from SR to RR carriage status. Additionally, a scenario with plasmid transfer from other pathogens to E. coli was analysed, see Supplementary text 4 and Figure S1.

Antibiotic use occurs in all populations - independent of infection. In the Dutch open population antibiotic courses are prescribed at a rate of 0.374 per year per person (23), and we assumed that $50 \%$ of persons receiving a course of antibiotics clear susceptible $E$. coli. Conceptually, this moves a subject from SS and SR to $S$ and R compartments, respectively, after which the likelihood of moving to SS, RR and SR increases (Figure $4 \mathrm{~b}$ ). For hospitalized patients we assumed that $33.8 \%$ received antibiotics on any given day, based on published data $(23,24)$. We did not consider repeated prescriptions in the open population or during hospitalization, as the intestinal flora will already be influenced by the first course of antibiotics. For changes in antibiotic use we also investigate a scenario with daily antibiotic use of $33.8 \%$ of all Dutch hospitalized subjects (24) and without antibiotic use in former patients and the open population. 
medRxiv preprint doi: https://doi.org/10.1101/2021.03.17.21253797; this version posted March 20, 2021. The copyright holder for this preprint (which was not certified by peer review) is the author/funder, who has granted medRxiv a license to display the preprint in perpetuity.

It is made available under a CC-BY-NC-ND 4.0 International license.

Furthermore, we modelled two scenarios of combined mechanisms. The "mixed scenario" combines $20 \%$ increased ARB hospital transmission with $20 \%$ increased ARB clearance in the open population, thereby maximizing the benefits of ARB among hospitalized patients, e.g., due to high selective antibiotic pressure, and maximizing fitness costs of ARB in the absence of selective antibiotic pressure. The "double benefit scenario" combines $20 \%$ increased ARB virulence (through increased selective antibiotic pressure) and 20\% increased hospital transmission of ARB (through both increased selective antibiotic pressure and higher contact rate by hospital staff acting as potential vectors), thereby maximizing the benefits of ARB in hospitalized patients. Scenarios and mechanisms are studied during time periods of 10 years, 50 years and infinite time (Table S5, S6 and S7 and Figure S2, S3 and S4).

\section{Acknowledgement and funding sources}

This research was part of the Risk and Disease burden of Antimicrobial Resistance (RaDAR) project, which was funded through the One Health European Joint Programme by the EU's Horizon-2020

Research and Innovation Programme (grant 773830).

\section{Competing Interest Statement}

The authors declare no competing interest. 
medRxiv preprint doi: https://doi.org/10.1101/2021.03.17.21253797; this version posted March 20, 2021. The copyright holder for this preprint (which was not certified by peer review) is the author/funder, who has granted medRxiv a license to display the preprint in perpetuity.

It is made available under a CC-BY-NC-ND 4.0 International license .

\section{References}

1. Ammerlaan HSM, Harbarth S, Buiting AGM, Crook DW, Fitzpatrick F, Hanberger $\mathrm{H}$, et al. Secular trends in nosocomial bloodstream infections: antibiotic-resistant bacteria increase the total burden of infection. Clin Infect Dis. 2013 Mar;56(6):798-805.

2. World Health Organization. Antimicrobial resistance global report on surveillance [Internet]. 2014. Available from: https://apps.who.int/iris/bitstream/handle/10665/112642/9789241564748_eng.pdf;jsessionid=FAF 3CA93BA29CAE7224A9B741E8E8C20?sequence $=1$

3. Temkin E, Fallach N, Almagor J, Gladstone BP, Tacconelli E, Carmeli Y. Estimating the number of infections caused by antibiotic-resistant Escherichia coli and Klebsiella pneumoniae in 2014: a modelling study. Lancet Glob Heal. 2018 Sep;6(9):e969-79.

4. Lipsitch M, Colijn C, Cohen T, Hanage WP, Fraser C. No coexistence for free: neutral null models for multistrain pathogens. Epidemics [Internet]. 2008/11/04. 2009 Mar;1(1):2-13. Available from: https://www.ncbi.nlm.nih.gov/pubmed/21352747

5. Beardmore RE, Gudelj I, Lipson DA, Hurst LD. Metabolic trade-offs and the maintenance of the fittest and the flattest. Nature. 2011 Apr;472(7343):342-6.

6. Schaufler K, Semmler T, Pickard DJ, de Toro M, de la Cruz F, Wieler LH, et al. Carriage of Extended-Spectrum Beta-Lactamase-Plasmids Does Not Reduce Fitness but Enhances Virulence in Some Strains of Pandemic E. coli Lineages. Front Microbiol. 2016;7:336.

7. Friedman ND, Temkin E, Carmeli Y. The negative impact of antibiotic resistance. Clin Microbiol Infect. 2016 May;22(5):416-22.

8. Andersson DI, Hughes D. Antibiotic resistance and its cost: is it possible to reverse resistance? Nat Rev Microbiol. 2010 Apr;8(4):260-71.

9. Farajzadah Sheikh A, Goodarzi H, Yadyad MJ, Aslani S, Amin M, Jomehzadeh N, et al. Virulenceassociated genes and drug susceptibility patterns of uropathogenic Escherichia coli isolated from patients with urinary tract infection. Infect Drug Resist. 2019;12:2039-47.

10. Baba T, Takeuchi F, Kuroda M, Yuzawa H, Aoki K, Oguchi A, et al. Genome and virulence determinants of high virulence community-acquired MRSA. Lancet (London, England). 2002 May;359(9320):1819-27.

11. Facinelli B, Spinaci C, Magi G, Giovanetti E, E Varaldo P. Association between erythromycin resistance and ability to enter human respiratory cells in group A streptococci. Lancet (London, England). $2001 \mathrm{Jul} ; 358(9275): 30-3$.

12. Sarkar S, Hutton ML, Vagenas D, Ruter R, Schüller S, Lyras D, et al. Intestinal Colonization Traits of Pandemic Multidrug-Resistant Escherichia coli ST131. J Infect Dis [Internet]. 2018 Aug 14;218(6):979-90. Available from: https://www.ncbi.nlm.nih.gov/pubmed/29471349

13. Vihta K-D, Stoesser N, Llewelyn MJ, Quan TP, Davies T, Fawcett NJ, et al. Trends over time in Escherichia coli bloodstream infections, urinary tract infections, and antibiotic susceptibilities in Oxfordshire, UK, 1998-2016: a study of electronic health records. Lancet Infect Dis [Internet]. 2018 Oct 1 [cited 2019 Nov 15];18(10):1138-49. Available from: http://www.ncbi.nlm.nih.gov/pubmed/30126643

14. World Health Organization. Global priority list of antibiotic-resistant bacteria to guide research, discovery, and development of new antibiotics [Internet]. Geneva; 2017. Available from: https://www.who.int/medicines/publications/WHO-PPL-Short_Summary_25FebET_NM_WHO.pdf?ua=1 
medRxiv preprint doi: https://doi.org/10.1101/2021.03.17.21253797; this version posted March 20, 2021. The copyright holder for this preprint (which was not certified by peer review) is the author/funder, who has granted medRxiv a license to display the preprint in perpetuity. It is made available under a CC-BY-NC-ND 4.0 International license .

15. Nijssen S, Florijn A, Bonten MJM, Schmitz FJ, Verhoef J, Fluit AC. Beta-lactam susceptibilities and prevalence of ESBL-producing isolates among more than 5000 European Enterobacteriaceae isolates. Int J Antimicrob Agents. 2004 Dec;24(6):585-91.

16. Ranjan A, Scholz J, Semmler T, Wieler LH, Ewers C, Müller S, et al. ESBL-plasmid carriage in E. coli enhances in vitro bacterial competition fitness and serum resistance in some strains of pandemic sequence types without overall fitness cost. Gut Pathog [Internet]. 2018;10(1):24. Available from: https://doi.org/10.1186/s13099-018-0243-z

17. de Kraker MEA, Jarlier V, Monen JCM, Heuer OE, van de Sande N, Grundmann H. The changing epidemiology of bacteraemias in Europe: trends from the European Antimicrobial Resistance Surveillance System. Clin Microbiol Infect [Internet]. 2013;19(9):860-8. Available from: http://www.sciencedirect.com/science/article/pii/S1198743X14632079

18. Mughini-Gras L, Dorado-García A, van Duijkeren E, van den Bunt G, Dierikx CM, Bonten MJM, et al. Attributable sources of community-acquired carriage of Escherichia coli containing $\beta$-lactam antibiotic resistance genes: a population-based modelling study. Lancet Planet Heal. 2019 Aug;3(8):e357-69.

19. Altorf-van der Kuil W, Schoffelen AF, de Greeff SC, Thijsen SF, Alblas HJ, Notermans DW, et al. National laboratory-based surveillance system for antimicrobial resistance: a successful tool to support the control of antimicrobial resistance in the Netherlands. Euro Surveill Bull Eur sur les Mal Transm = Eur Commun Dis Bull. 2017 Nov;22(46).

20. Cooper BS, Medley GF, Stone SP, Kibbler CC, Cookson BD, Roberts JA, et al. Methicillinresistant Staphylococcus aureus in hospitals and the community: stealth dynamics and control catastrophes. Proc Natl Acad Sci U S A. 2004 Jul;101(27):10223-8.

21. Haverkate MR, Platteel TN, Fluit AC, Cohen Stuart JW, Leverstein-van Hall MA, Thijsen SFT, et al. Quantifying within-household transmission of extended-spectrum $\beta$-lactamase-producing bacteria. Clin Microbiol Infect [Internet]. 2017 Jan 1 [cited 2019 Nov 15];23(1):46.e1-46.e7. Available from: https://www.sciencedirect.com/science/article/pii/S1198743X16303603

22. van den Bunt G, van Pelt W, Hidalgo L, Scharringa J, de Greeff SC, Schurch AC, et al. Prevalence, risk factors and genetic characterisation of extended-spectrum beta-lactamase and carbapenemase-producing Enterobacteriaceae (ESBL-E and CPE): a community-based crosssectional study, the Netherlands, 2014 to 2016. Euro Surveill Bull Eur sur les Mal Transm = Eur Commun Dis Bull. 2019 Oct;24(41).

23. de Greeff SC, Mouton JW. NethMap 2018: Consumption of antimicrobial agents and antimicrobial resistance among medically important bacteria in the Netherlands / MARAN 2018: Monitoring of Antimicrobial Resistance and Antibiotic Usage in Animals in the Netherlands in 2017 [Internet]. Rijksinstituut voor Volksgezondheid en Milieu RIVM; 2018. Available from: https://rivm.openrepository.com/bitstream/10029/622042/2/2018-0046.pdf

24. Akhloufi H, Streefkerk RH, Melles DC, de Steenwinkel JEM, Schurink CAM, Verkooijen RP, et al. Point prevalence of appropriate antimicrobial therapy in a Dutch university hospital. Eur $\mathrm{J}$ Clin Microbiol Infect Dis. 2015 Aug;34(8):1631-7. 
medRxiv preprint doi: https://doi.org/10.1101/2021.03.17.21253797; this version posted March 20, 2021. The copyright holder for this preprint (which was not certified by peer review) is the author/funder, who has granted medRxiv a license to display the preprint in perpetuity.

It is made available under a CC-BY-NC-ND 4.0 International license .

\section{Figures and tables}

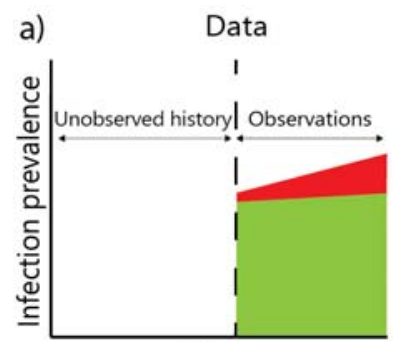

Time ->

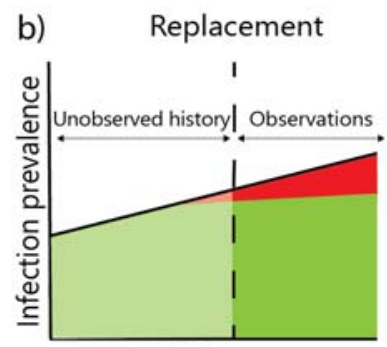

Time $->$

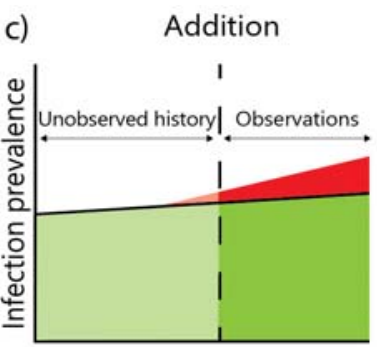

Time -> d) Replacement and addition

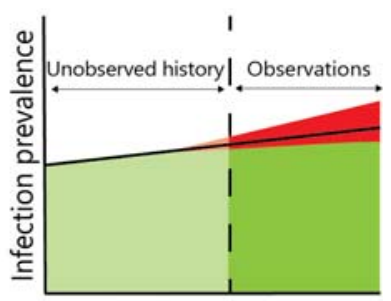

Time ->

\section{(20us}

Resistant infections

Susceptible infections

Expected number of infections without resistance having developed

- - - Point in time after which we observe (have data on) the number of infections

Figure 1. Three scenarios explained by addition to and replacement of susceptible infections The observed prevalence of susceptible and resistant infections is depicted in panel a. In panel b, c and $d$, three potential scenarios for the prevalence in the unobserved period are depicted. Each scenario suggests a different interpretation regarding addition or replacement.

Observations
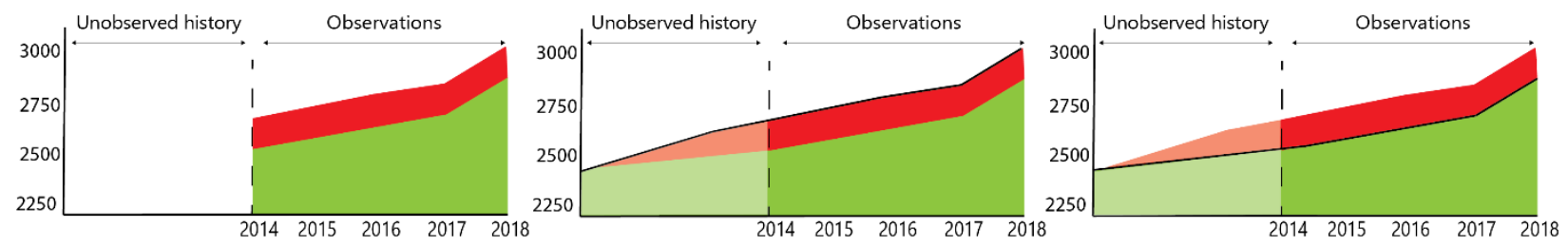

\section{Resistant infections}

\section{Susceptible infections}

- Expected number of infections without resistance having developed

- - - Point in time after which we observe (have data on) the number of infections

Figure 2. Number of susceptible E. coli and ESBL E. coli bacteraemia in 24 Dutch hospitals from 2014 to 2018 
medRxiv preprint doi: https://doi.org/10.1101/2021.03.17.21253797; this version posted March 20, 2021. The copyright holder for this preprint (which was not certified by peer review) is the author/funder, who has granted medRxiv a license to display the preprint in perpetuity.

It is made available under a CC-BY-NC-ND 4.0 International license .

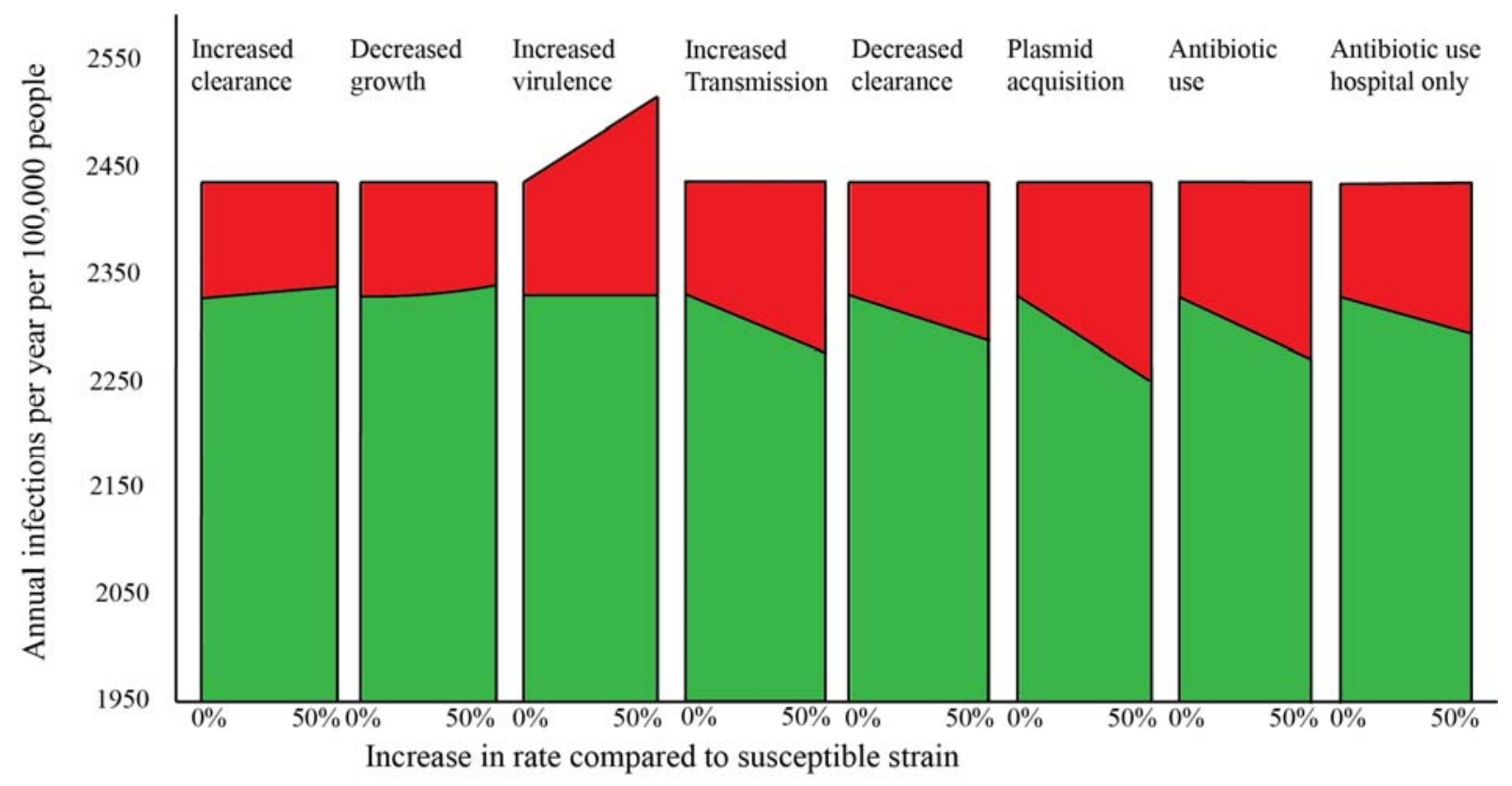

Susceptible infections

Resistant infections

Figure 3. Annual susceptible and resistant infections per 100,000 people per mechanism in 10 years of time.
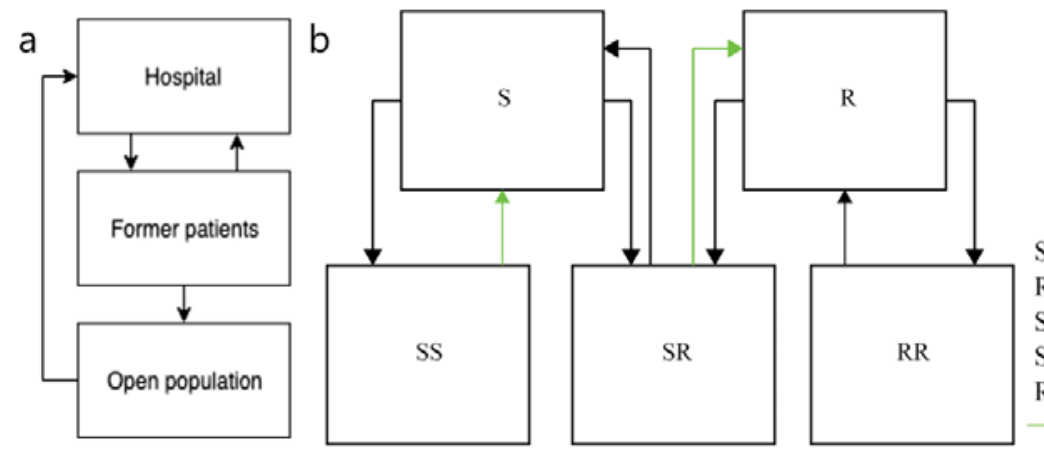

$\mathrm{S}=$ Colonised with a susceptible strain $\mathrm{R}=$ Colonised with a resistant strain

SS $=$ High density colonised with susceptible strains $\mathrm{SR}=$ Colonised with susceptible and resistant strain $\mathrm{RR}=$ High density colonised with resistant strains $\rightarrow=$ Routes forced due to antibiotic use

Figure 4. Compartmental model of ESBL E. coli and E. coli colonisation states 